\title{
BC adds ethnic diversity to new public cord blood bank
}

$\mathrm{U}$ ntil recently, there was just one place for cord blood at the British Columbia Women's Hospital \& Health Centre in Vancouver - and that was in the medical waste bin. But as of mid-2014, much of the blood contained in those stem cells will be rescued and put to use. In January, the hospital was named as one of four Canadian collection sites, along with institutions in Ottawa, Ontario, Brampton, Ont. and Edmonton, Alberta, for the new National Public Cord Blood Bank. All four sites are now collecting cord blood for validation purposes and will open officially later in 2014.

Cord blood stem cell transplants are used to treat more than 50 blood-related diseases and disorders. About 1000 Canadians are waiting for a stem cell transplant today, but Canadian Blood Services (CBS) can usually find matches for only half of them - even with access to over 22 million unrelated adult donors. CBS also has access to over 600000 publicly banked cord blood units through the World Marrow Donor Association's international database for stem cells, but the cost to import a unit of cord blood is $\$ 42000$.

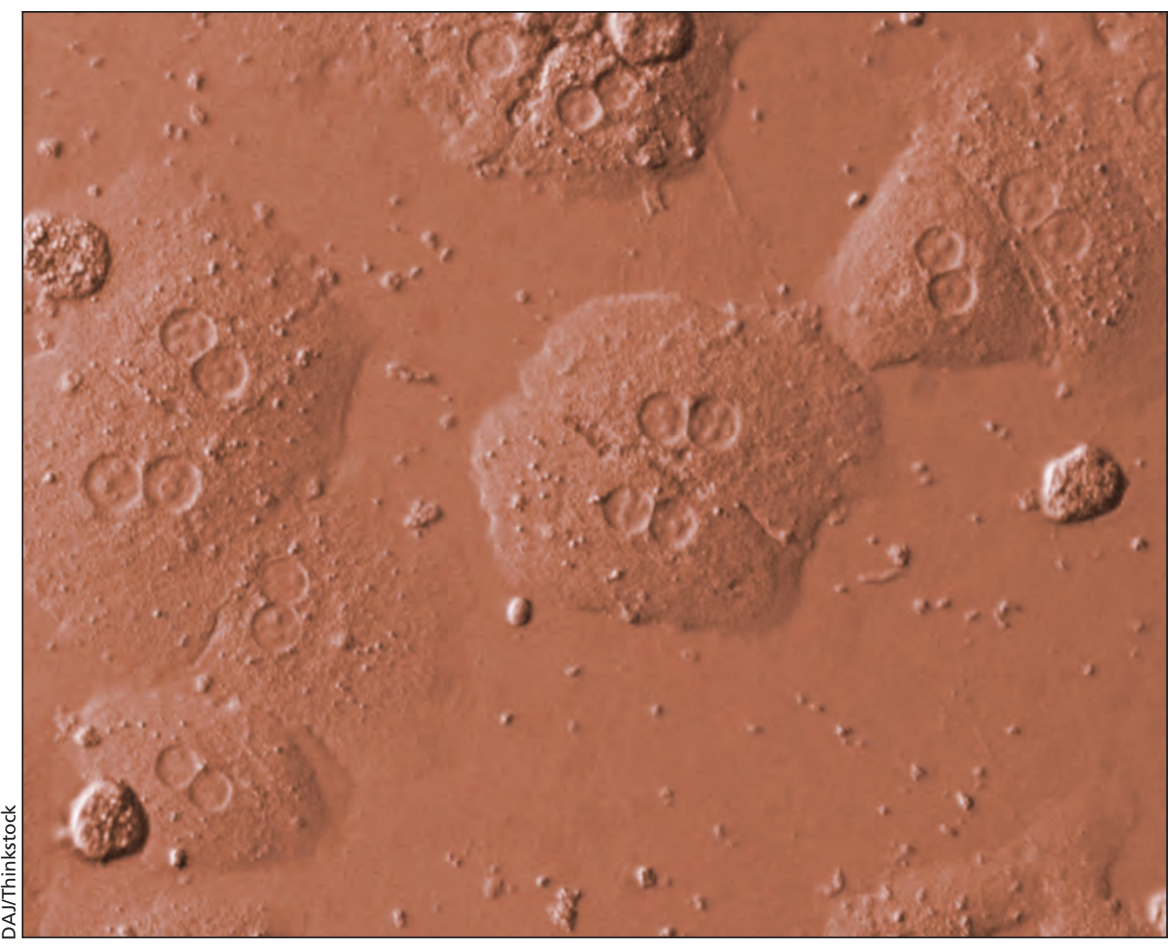

Cord blood stem cells, such as those depicted above in an electron microscopic image, are used to treat more than $\mathbf{5 0}$ blood-related diseases and disorders.
There are about 7000 births a year at BC Women's Hospital, with up to $40 \%$ representing ethnically diverse groups. The hospital has allocated a room for cord blood collection, and the National Public Cord Blood Bank provides round-the-clock staffing. "We did an analysis and we believe that what we've set up with CBS is cost-neutral," said Christilaw. "But we also think that creating a collection site here is the right thing to do. From the point of view of the Canadian public, it's time we did this - in fact, it's overdue."

Christilaw doesn't expect it will be difficult to encourage delivering mothers to donate their babies' cord blood to the bank. "The choice is one of discarding something you really can't use, or donating it, so for a woman needing to make this choice, there's no real downside to her choosing to donate her cord blood." The hospital has reached out to ethnic groups like the Vancouver Chinese community and the South Asian community, both of which have been wholeheartedly supportive. The hospital is hoping to collect cord blood from $75 \%$ of the eligible population, about 3000 donors a year, once the program is fully operational.

Dr. Robert Casper, medical director and founder of the Insception LifeBank Cord Blood Program in Toronto, Ont., a private cord-bank facility, said it's unlikely that the new National Public Cord Bank will affect the number of clients who choose to preserve and store their infants' cord blood at private companies. "It might even have a positive impact on our work," he reflected. "Having the government endorse banking of cord blood will move people to realize that cord blood is a valuable resource that should be saved, not thrown away," he said. "It validates the idea that banking cord blood is an important thing to do. And for those people who cannot afford to pay for private banking of cord blood, it takes the pressure off because they know there will be lots of samples in the Canadian bank." - Lauren Kramer, Richmond, BC 